\title{
POTENCIALIDADES DA HISTÓRIA ORAL NA PESQUISA E NA FORMA(AÇÃO) DOCENTE: percurso metodológico
}

Vilmar José Borges Jullizze Maia Borges

Resumo

O presente artigo tem por objeto de estudo os pressupostos metodológicos de pesquisa da História Oral, e, por objetivo, desvelar e socializar as potencialidades dessa abordagem como alternativa para investigar as especificidades da relação entre os diferentes saberes/fazeres que envolvem a formação e a atuação docente. Para tanto, apoiados na abordagem da pesquisa bibliográfica, destaca a necessidade de investigações que voltem seus olhares para a internalidade do processo educativo, desvelando saberes e fazeres dos sujeitos em seus dinâmicos processos formativos. Nessa direção, enfatiza as potencialidades da História Oral. Conclui-se que essa abordagem se mostra ainda mais potente ao permitir ao pesquisador adotar, em suas pesquisas, um híbrido constituído por dois ou mais procedimentos, que podem se relacionar sem causar danos teórico-metodológicos a cada um separadamente.

Palavras-chave: história oral; saberes docentes; metodologia de pesquisa.

\section{PO'TENTIALITIES OF ORAL HISTORY IN RESEARCH AND TEACHING TRAINING: methodological path}

\begin{abstract}
This article aims to study the methodological assumptions of Oral History research and thus unveil and share the potential of this approach as an alternative to investigate the specificities of the relationship between the different knowledge-and-actions concerning teacher training and performance. Thus, grounded on bibliographical research, it highlights the need for investigations focused on the internality of the educational process, revealing the subjects' knowledge-and-action in their dynamic teacher training processes. In this direction, it emphasizes the potential of Oral History. We conclude that this approach is even more powerful so as to allow researchers to adopt a hybrid model consisting of two or more procedures, which can be related without causing theoretical and methodological damage to each one separately.
\end{abstract}

Keywords: oral history; teaching knowledge; research methodology.

\section{PO'TENCIAL DE LA HISTORIA ORAL EN LA INVESTIGACIÓN Y EN FORMACIÓN DOCENTE: trayectoria metodológica}

\section{Resumen}

El propósito de este artículo es estudiar los supuestos metodológicos de la investigación en Historia Oral, y, por objetivo, desvelar y socializar las potencialidades de este enfoque como alternativa para investigar las especificidades de la relación entre los diferentes saberes / prácticas que involucran la formación y el desempeño docente. Para ello, apoyados en el enfoque de la investigación bibliográfica, destacamos la 
necesidad de investigaciones que se enfoquen en interiorizarse en el proceso educativo, revelando los conocimientos y acciones de los sujetos en sus dinámicos procesos formativos. Con estos delineamientos, enfatiza el potencial de la Historia Oral. Concluimos que este enfoque es aún más potente al permitir que el investigador adopte, en sus investigaciones, un híbrido que consista en dos o más procedimientos, que pueden relacionarse sin causar daño teórico y metodológico a cada uno por separado.

Palabras clave: historia oral; conocimiento docente; metodología de la investigación.

\section{INTRODUÇÃO}

Em suas buscas por contribuir com a formação e a atuação docente, os pesquisadores enfrentam múltiplos desafios, entre eles a definição da abordagem metodológica da pesquisa. Esse obstáculo se acentua quando a investigação visa desvelar justamente a complexidade desse campo de investigação, com foco nas especificidades da relação entre os diferentes saberes/fazeres que envolve a formação e a atuação desse profissional. Mediante tal complexidade, destaca-se como questão problematizadora: a abordagem de pesquisa da História Oral pode contribuir para o não aprisionamento da pluralidade de saberes que são cotidianamente mobilizados, produzidos e reproduzidos no processo de constituição da identidade profissional e que, muitas vezes, quando não pesquisados e socializados ficam confinados aos segredos do professor em seu labor no espaço das salas de aula?

A busca por respostas possíveis ao questionamento acima sinaliza que um caminho viável passa pela necessidade de voltar nossos olhares para a internalidade do processo educativo, buscando ouvir e socializar vozes de professores no seu constante processo de ser/se fazer/sendo professores (NÓVOA, 2013). É nesse cenário que situamos nossas reflexões acerca das potencialidades da abordagem metodológica de pesquisa da História Oral (BOM MEIHY, 1996; DELGADO, 2007; THOMPSON, 1998), no âmbito da pesquisa de caráter qualitativo, visto que esse tipo de abordagem pode responder às várias questões específicas da formação e da atuação docente, bem como de sua rizomática relação.

Segundo Bogdan e Biklen (2013, p. 49), a investigação qualitativa “[...] exige que o mundo seja examinado com a ideia de que nada é trivial, que tudo tem potencial para constituir uma pista que nos permita estabelecer uma compreensão mais esclarecedora do nosso objeto de estudo". E, ainda, segundo os referidos autores, são características básicas de uma investigação qualitativa em educação: a busca de dados no ambiente em que se encontram os sujeitos; a descrição dos fenômenos, conforme os significados expressos no ambiente; o foco nos processos e não apenas no produto, isto é, como as pessoas constroem os significados e suas representações e, ainda, a análise dos dados elaborada de forma indutiva, ou seja, o investigador não recolhe dados com o objetivo de confirmar hipóteses construídas previamente, pelo contrário, as abstrações são construídas à medida que os dados vão sendo coletados e categorizados.

Nessa direção, e considerando o fato de que a relação entre formação e a atuação docente se constitui em um fenômeno complexo, dinâmico e que envolve aspirações, crenças, valores e atitudes dos sujeitos envolvidos, é que são imprescindíveis os pressupostos da pesquisa qualitativa, visto que a mesma, conforme bem salientam Lüdke e André (2013), por considerar a realidade complexa e contextualizada, tem um plano aberto e flexível, sendo rica em dados descritivos.

Ressalta-se ainda, que a pesquisa de caráter qualitativo não admite regras aplicáveis igualmente a todos os casos, exigindo do pesquisador opção pelas mesmas, bem como por nível de inflexão delas, tendo em vista a especificidade de seu objeto de estudo. Essa opção torna-se 
DOI: $10.12957 /$ teias. $\%$ Y.50659

mais complexa quando se leva em conta que é no decorrer do processo de investigação que o objeto de pesquisa começa a ser compreendido e delineado, conforme nos advertem Bogdan e Biklen (2013):

Para um investigador qualitativo que planeja elaborar uma teoria sobre o seu objeto de estudo, a direção dessa só se começa a estabelecer após a recolha dos dados e o passar de tempo com os sujeitos. Não se trata de montar um quebracabeça cuja forma final conhecemos de antemão. Está-se a construir um quadro que vai ganhando forma à medida que se recolhem as partes. $O$ processo de análise é como um funil: as coisas estão abertas de início e vão-se tornando mais fechadas e específicas no extremo (BOGDAN, BIKLEN, 2013, p. 50).

Assim, no âmbito da pesquisa com abordagem qualitativa, a constituição de fontes nos limites da História Oral apresenta ricas possibilidades. Esse potencial se acentua, principalmente, ao privilegiar o estabelecimento de técnicas e procedimentos de coleta, de registro, de salvaguarda, de controle e de estudo das informações orais a serem resgatadas pelos pesquisadores junto aos atores sociais que disponibilizam interpretações dos acontecimentos que vivenciaram, conforme salientam Bom Meihy (1996), Santos (2010), Delgado (2007), entre outros.

Segundo Bom Meihy (1996),

História oral é um recurso moderno usado para a elaboração de documentos, arquivamento e estudos referentes à vida social de pessoas. Ela é sempre uma História do tempo presente e também conhecida por História viva. [...] a História Oral se apresenta como forma de captação de experiências de pessoas dispostas a falar sobre aspectos de sua vida mantendo um compromisso com o contexto social (BOM MEIHY, 1996, p. 13).

Portanto, a História Oral se apresenta como uma forma do fazer histórico, intimamente relacionada com os acontecimentos do tempo presente. Ela possibilita o resgate de diferentes interpretações acerca da história vivida, constituindo-se em uma forma democrática do fazer histórico, possibilitando ao pesquisador o contato com os atores sociais e suas lembranças, esquecimentos, ressentimentos e sentimentos (POLLAK, 1992; ROUSSO, 2006).

Assim, essa abordagem metodológica de pesquisa se mostra potente e adequada nas propostas investigativas que visem contribuir para desvelar a complexidade e processualidade do processo de constituição da identidade docente (NÓVOA, 2013; MOITA, 2013), captando e documentando o movimento do ser/se fazer/sendo professor. Possibilita documentar o não documentado (BOM MEIHY, 1996), ao resgatar e registrar relatos e narrativas acerca de experiências e vivências docentes no exercício da profissão.

Para Thompson (1998),

A História oral oferece, quanto a sua natureza, uma fonte bastante semelhante à autobiografia publicada, mas de muito maior alcance [...]. A realidade é complexa e multifacetada; e um mérito principal da História oral é que, em muito maior amplitude do que a maioria das fontes, permite que se recrie a multiplicidade original de pontos de vista (THOMPSON, 1998, p. 25-6).

Muito embora a História Oral remonte à Antiguidade, seu uso sistemático é um fenômeno recente que remonta a meados do século XX, sobretudo entre os anos 1960 e 1980 
(THOMPSON, 1998). Conforme Louro (1990), a História Oral é, provavelmente, a mais antiga forma de reconstituir a História. No entanto, essa abordagem ficou no abandono por longo tempo, provavelmente devido à concepção positivista de ciência do século XIX, que atribuiu extrema importância aos documentos e na exigência da exatidão, comprovação dos fatos, documentação e neutralidade do pesquisador. Assim, é relativamente recente a utilização da História Oral nos meios acadêmicos, sobretudo em estudos sobre processos/fenômenos próprios da Educação escolarizada.

Segundo Moss (1991), a versão moderna da História Oral começou a ser desenvolvida após a Segunda Guerra Mundial, devido a três fatores: a atmosfera democrática mais favorável às discussões sobre a História da humanidade; a revolução tecnológica e industrial, que tem acompanhado essa democratização da humanidade; e, em consequência dos acontecimentos mencionados, a utilização de procedimentos mais tecnológicos a serviço de uma História social mais democrática.

Santos (2010), aponta que a moderna História Oral teve significativo avanço com os estudos realizados na escola de sociologia de Chicago, nos anos de 1920. Com característica militante e politicamente engajada, a História Oral britânica nasce nos anos de 1960, quando antropólogos e sociólogos abrem a História operária em uma perspectiva social, abarcando estudos sobre a vida cotidiana dos trabalhadores. Essa perspectiva militante da História Oral também toma expressividade, nesse período, em outros países como Itália e Alemanha.

Ainda segundo Santos (2010), na França, devido a uma forte desconfiança dos historiadores frente à História Oral, ela só tomou impulso para as primeiras pesquisas a partir de 1970, conquistando sua legitimação entre as ciências sociais históricas somente nos anos 1980.

A obra "A voz do passado", de Paul Thompson, publicada em 1978, é um marco para o desenvolvimento da ideia de que a função da História Oral é democratizar a própria História, um processo de devolvê-la ao povo, evidenciando um alargamento no campo de ação da História Social ao fazer a história não só dos líderes da sociedade, mas daqueles que são desconhecidos, que não têm voz, que são postos à margem, enfim, dos excluídos (THOMPSON, 1998).

Foi também nos anos de 1970, com estudos desenvolvidos pelo Centro de Pesquisas e Documentação de História Contemporânea - CPDOC, da Fundação Getúlio Vargas, que surgiram as primeiras produções científicas pautadas na História Oral, desenvolvidas no Brasil. No entanto, sua expressividade nos meios acadêmicos só aconteceu a partir do início dos anos 1990, com significativos trabalhos desenvolvidos pela Associação Brasileira de História Oral ABHO, da Universidade de São Paulo.

Discutindo essa tardia utilização da História Oral por pesquisadores brasileiros, Santos (2010) aponta dois obstáculos principais tidos como os responsáveis por ela. O primeiro refere-se ao fato que nos anos de 1970 esse referencial teórico-metodológico ainda era um terreno movediço, sem uma estabilidade acadêmica consistente, o que gerava inúmeros questionamentos e dúvidas. Outro obstáculo, segundo a referida autora, é a constatação de que a História Oral, ao “[...] dar vozes aos vencidos e excluídos" (THOMPSON, 1998), constituía uma ameaça à censura do regime político militar vivenciado pelo Brasil nos anos de 1970 e no início dos anos de 1980, o que situava os trabalhos que se utilizavam da metodologia da História Oral em um campo minado.

Atualmente essa abordagem metodológica já se encontra bastante consolidada e, ao mesmo tempo em que entrelaça compreensões de vários campos de estudo - como a História, a Sociologia e a Antropologia, por exemplo - a História Oral mantém a tradição de mobilizar parâmetros qualitativos de investigação que se apoia na oralidade, na coleta de vozes que, de 
maneiras variadas, são analisados sob várias perspectivas e constituem novas informações, sendo, portanto, uma forma de caracterizar os fenômenos da experiência humana e, nesse caso, seu estudo é apropriado em muitos campos das ciências sociais.

No entanto, por apoiar-se na oralidade, sua fonte de investigação é um documento que surge de entrevistas gravadas, em que a verdade está na versão do narrador. Para narrar sua versão, o sujeito utiliza-se de suas memórias e, nesse sentido, pode haver um julgamento da confiabilidade da memória, como expressão de veracidade. Tal fato é enfrentado por Camargo (1993), ao afirmar que

O mínimo que podemos dizer é que a História Oral é uma fonte, um documento, uma entrevista gravada que podemos usar da mesma maneira que usamos uma notícia de jornal, ou uma referência em um arquivo, em uma carta. [...] E pensar se a História Oral é objetiva ou não, seria realmente pouco relevante, na medida em que nenhuma fonte é objetiva. Toda fonte, em princípio, é provida de objetividade, mas é também um fator de desconfiança e, evidentemente, pode ser um indutor do equívoco (CAMARGO, 1993, p. 78)

Thompson (1998) também nos fornece fortes subsídios para sustentação da proposta pela abordagem metodológica da História Oral como procedimento técnico de pesquisas voltadas, principalmente, para a (form)ação docente, ao afirmar que não há fontes totalmente seguras, visto que tanto o oral como o escrito podem ser modificados, corrompidos. O autor admite que o processo da memória depende da percepção e de como esse processo se objetivou e, portanto, os materiais de entrevistas representam percepções sociais de fatos, bem como estão sujeitos a pressões sociais dos seus contextos de origem. Evidencia-se, assim, a potencialidade da História Oral como apoio e sustentação para desvelar sinais e pistas da rizomática relação formação/ação/formação docente, principalmente por propiciar a obtenção de saberes e fazeres, que são permanentemente produzidos, reproduzidos e mobilizados no exercício da função docente.

A História Oral propicia aos estudiosos e pesquisadores da área valorizar as vivências dos professores ao contribuir para revelar detalhes que documentos oficiais não informariam. Para Thompson (1998) é um equívoco histórico valorizar somente o que está escrito; pois a história só possui verdadeiro sentido ao desvelar sua finalidade social e é através da História Oral que se faz possível evidenciar os fatos coletivos.

Enquanto os historiadores estudarem os atores da história à distância, a caracterização que fazem de suas vidas, opiniões e ações sempre estará sujeita a ser descrições defeituosas, projeções da experiência e da imaginação do próprio historiador: uma forma erudita de ficção. A evidência, transformando os "objetos" de estudo em "sujeitos", contribui para uma história que não só é mais rica mais viva e mais comovente, mas também verdadeira (THOMPSON, 1998, p. 137).

E, continua o referido autor, asseverando que a coleta de fontes orais, realizadas por meio de entrevistas, possibilita ao pesquisador dar voz a importantes atores sociais, que muitas vezes são silenciados por pesquisas pautadas em tendências historiográficas tradicionais ao deixarem tais sujeitos de lado. Ao dar voz a tais sujeitos, contribui-se para revelar suas experiências de vida, seus saberes, seus fazeres e suas visões de mundo. 
A história oral é uma história construída em torno de pessoas. Ela lança a vida para dentro da própria história e isso alarga seu campo de ação. Admite heróis vindos não só dentre os líderes, mas dentre a maioria desconhecida do povo. Estimula professores e alunos a se tornarem companheiros de trabalho. Traz a história para dentro da comunidade e extrai a história de dentro da comunidade. Ajuda os menos privilegiados, e especialmente os idosos, a conquistar dignidade e autoconfiança. Propicia o contato - e, pois, a compreensão - entre classes sociais e entre gerações. E para cada um dos historiadores e outros que partilhem das mesmas intenções, ela pode dar um sentimento de pertencer a determinado lugar e a determinada época. Em suma, contribui para formar seres humanos mais completos. Paralelamente, a história oral propõe um desafio aos mitos consagrados da história, ao juízo autoritário inerente a sua tradição. E oferece os meios para uma transformação radical no sentido social da história (1998, p.44).

Falar de História Oral como metodologia na pesquisa historiográfica implica reconhecer três tendências nas pesquisas que a utilizam como abordagem metodológica: a História Oral de Vida, a História Oral Temática e a Tradição Oral. E, conforme Bom Meihy (1996), as três tendências dependem de entrevistas gravadas.

A História Oral de Vida é caracterizada pelos estudos biográficos, centrados nos acontecimentos relacionados à vida de um indivíduo, suas experiências, identidade e memória individual. Portanto, o depoente é o sujeito primordial e tem liberdade para dissertar o mais livremente possível sobre sua experiência pessoal. Nesse caso, as narrativas orais não são apenas fontes de informações para o esclarecimento de problemas do passado, ou um recurso para preencher lacunas da documentação escrita. Nessa tendência, as narrativas dão relevância as vivências e as representações individuais.

Conforme Bom Meihy (1996, p. 35), “[...] a História Oral de Vida é o retrato oficial do depoente. Nessa direção, a verdade está na versão oferecida pelo narrador, que é soberano para revelar ou ocultar casos, situações e pessoas". Assim, as experiências dos homens, constitutivas de suas trajetórias, são rememoradas, reconstruídas e registradas a partir do encontro de dois sujeitos: pesquisado e pesquisador.

Já a modalidade da Tradição Oral caracteriza-se pelos estudos relacionados ao conhecimento histórico, transmitido oralmente ao longo tempo pelo saber não sistematizado, pelos costumes que são transmitidos de geração a geração. Nesse caso, o sujeito é sempre mais coletivo e remete às questões do passado que geralmente se manifestam pelo que chamamos de folclore.

Os casos de tradição oral implicam o uso do que se chama de narrativas emprestadas. Como para a explicação do presente a tradição oral necessita da retomada de aspectos transmitidos por outras gerações, dá-se o empréstimo do patrimônio narrativo alheio, quase sempre herdado dos pais, avós e dos velhos (BOM MEIHY, 1996, p. 47).

Segundo Vansina (1968), as sociedades orais utilizam a fala como meio de preservação de suas tradições, mitos, valores que são transmitidos de uma geração para outra. Assim, para as pesquisas que se apoiam nos pressupostos da Tradição Oral, o grupo tem mais importância que o indivíduo em si, pois faz parte dessa tradição tudo aquilo que o coletivo considera importante para o funcionamento e a existência daquela sociedade. Os mitos e as explicações do mundo, as 
festas, os ritos, os costumes, os hábitos domésticos integram esse conjunto de tradições que é transmitido pela memória oral.

Já a História Oral Temática é caracterizada pelos estudos temáticos, centrados em acontecimentos relacionados às experiências, memórias e identidade de grupo/coletividades sociais. Nesse caso, privilegia a coleta de depoimentos orais que esclarecem determinados temas. Sua tendência parte de um assunto específico, tematizado, preestabelecido, e, portanto, a objetividade é mais direta, pois as entrevistas podem estar direcionadas a compreender um tema determinado, que é parte das experiências vivenciais do depoente.

Segundo Bom Meihy (1996),

Dado seu caráter específico, a História oral temática tem características bem diferentes da História oral de vida. Detalhes da História pessoal do narrador apenas interessam na medida em que revelam aspectos úteis à informação temática central (BOM MEIHY, 1996: 41)

Nessa direção, conforme bem salienta Garnica (2003), o trabalho com História Oral Temática, ainda que, como na História de Vida, constitua-se pautado nos depoimentos orais recolhidos de pessoas particularmente significativas para o problema focalizado pelo pesquisador, centra-se mais em um conjunto limitado de temas. Ao reconstituir "aspectos" da vida dos entrevistados, busca auscultar partes de experiências de vida, recortes previamente selecionados pelo pesquisador. Certamente que, dada a atmosfera em que se espera transcorra a entrevista, fatos que deslizem para fora do campo temático previamente definido pelo pesquisador são também considerados, mas não terão, necessariamente, papel decisivo na interpretação da narrativa colhida.

$\mathrm{Na}$ modalidade da História Oral Temática, o pesquisador precisa ter claro o problema a ser pesquisado, para que possa obter do colaborador aquilo que é essencial para o seu trabalho. Para tanto, o pesquisador deve conduzir a entrevista, evitando digressões, o supérfluo e o desnecessário. Nessa modalidade, ao utilizar a técnica de "depoimentos pessoais", determinados acontecimentos da vida de seu informante só vão interessar ao pesquisador se aqueles fatos e relatos se inserirem diretamente no trabalho, portanto, essa abordagem é mais objetiva.

As três tendências dessa abordagem metodológica de pesquisa (História Oral de Vida, Tradição Oral e História Oral Temática) exploram as relações entre memória e História e possibilitam a recuperação da arte de narrar.

Segundo Santos (2010), a memória é a base da História Oral e as vozes e depoimentos dos colaboradores se apoiam em suas próprias memórias e, portanto, são um valioso recurso para a constituição da história do cotidiano, haja vista que o passado é o principal suporte da identidade humana e como tal não pode se perder. Por isso, pensar na memória como fonte significa pensá-la como categoria que não se separa do tempo nem da experiência. A memória faz parte de um processo dinâmico que busca significados que vão reestruturando os elementos que, ao serem narrados, desencadeiam lembranças, no sentido de reordená-los, conservá-los ou excluílos e alimenta-se, nesse processo.

Para Bosi (1994, p. 11), "[...] a memória aparece como força subjetiva ao mesmo tempo profunda e ativa, latente e penetrante, oculta e invasora”. Assim, se as memórias são experiências, fontes, matérias-primas da história que tem como tarefa reconstruir o passado, também são experiências que se vive no interno, que permitem relacionar o presente com o passado e ao mesmo tempo pode interferir no processo atual das representações. 
Nessa direção, diante do fato de que a História Oral, conforme salienta Bom Meihy (1996, p. 13) "[...] ...é sempre uma História do tempo presente e também conhecida por História viva", que "[...] se apresenta como forma de captação de experiências de pessoas dispostas a falar sobre aspectos de sua vida", pode-se afirmar que as fontes historiográficas criadas com a História Oral são disparadas pela oralidade e começam a ser constituídas em momentos de entrevista. Portanto, tem como matéria-prima os depoimentos. E, ainda, a matéria-prima dos depoimentos com os quais trabalhamos na História Oral são as lembranças, são as memórias.

Conforme Benjamin (2012), um aspecto importante e decisivo para a narrativa é a memória, pois um homem sem memória não tem o que narrar. Segundo o autor, a memória é a "musa da narrativa", porque permite reinventar-se, reinterpretar-se. Nesse sentido, um professor, quando rememora suas experiências e memórias, articula passado e presente, transformando e retomando, entre idas e vindas, significados e sentidos ambivalentes.

A memória, seja ela entendida como experiência no tempo ou como vivência de um passado presentificado, seja entendida como registro subjetivo de experiências dadas pela significação que pode assumir para o narrador, poderá possibilitar compreensões e desvelamentos acerca das escolhas, opções, circunstâncias e contingências que permeiam a docência. Assim, partir de informações/vozes e compreender suas lógicas na docência, naquilo que as representam, que as identificam e que as sustentam, pode fornecer elementos que ressignificam sua identidade e suas práticas docentes.

Nesse sentido, em Benjamin (2012), encontramos sustentação para asseverar que o desenvolvimento da pesquisa com a História Oral, propicia potentes narrativas quando ocorre o estabelecimento de uma interação entre o sujeito que narra (entrevistado) e o ouvinte (entrevistador). Segundo ele, a fonte de histórias a que recorrem todos os narradores são as experiências que passam de pessoa a pessoa e "[...] o narrador retira da experiência o que ele conta: sua própria ou a relatada pelos outros. E incorpora as coisas narradas à experiência de seus ouvintes" (BENJAMIN, 2012, p. 201). Ainda segundo o referido autor, estamos constantemente narrando e, muitas vezes, nem nos damos conta disso. Histórias das mais variadas vêm à tona quando alguém nos conta uma. Quase que de imediato lembramo-nos de algo que também gostaríamos de contar: uma narrativa puxa a outra.

A utilização da História Oral como pressuposto metodológico de pesquisa exige do pesquisador uma série de procedimentos. Como ponto de partida, a elaboração de um projeto e sua continuidade passa pela seleção do grupo de pessoas que serão entrevistadas, sendo que tal seleção deve pautar em critérios que levem em consideração a perseguição dos objetivos da pesquisa, conforme bem salientam Bom Meihy e Holanda (2010),

Um conjunto de procedimentos que se inicia com a elaboração de um projeto e que continua com o estabelecimento de um grupo de pessoas a serem entrevistados. O projeto prevê: planejamento da condução das gravações com definição de locais, tempo de duração e demais fatores ambientais; transcrição e estabelecimento de textos; conferência do produto escrito; autorização para uso; arquivamento e, sempre que possível, a publicação dos resultados que devem, em primeiro lugar, voltar ao grupo que gerou as entrevistas. (BOM MEIHY, HOLANDA, 2010: 15)

Assim, como bem sinaliza Marzochi (2013), e segundo a perspectiva defendida por Bom Meihy e Holanda (2010), a História Oral se constitui em uma parte do conjunto de fontes orais, cuja principal manifestação se materializa por intermédio da entrevista. No entanto, há que se 
registrar que a entrevista não é uma exclusividade da história oral e, ainda, que apenas adotar a realização de entrevistas, na coleta de dados empíricos, não é fazer história oral.

Para melhor compreensão, embora não discutindo especificamente a questão da História Oral, pertinente aqui as contribuições de Carvalhais (s/d), ao discutir a dualidade que envolve a palavra entrevista. Segundo a referida autora, ao abandonar a busca pela origem etimológica e brincando com a palavra, percebeu duas palavras distintas: "entre e vistas". Daí a origem das duas perspectivas do ato de entrevistar, de se colocar em um lugar de "entre olhares". Pode-se optar pelo "entre ver" o outro, num jogo de véus e de sombras; como também, no sentido do "dar-se a ver", de estarmos olhos nos olhos, perante o entrevistado que se deixa ver pelo entrevistador, que, por sua vez, se deixa ver pelo entrevistado, transformando o momento da "entre vista" em um momento de "dar-se a ver", em uma mútua troca de experiências.

Portanto, toda História Oral utiliza-se da entrevista. E, nesse caso, a entrevista deve ir além da mera realização do entrevistar. Deve constituir-se em um momento de troca de experiência, sendo importante criar um ambiente que propicie o estabelecimento de uma relação de cumplicidade entre pesquisado e pesquisador. Em consequência, conforme assevera Bom Meihy (1996), tal abordagem de pesquisa só pode ser realizada mediante a composição mínima de três elementos combinados, que não fazem sentido se não juntos, ou seja, necessita do entrevistador; do entrevistado e da aparelhagem de som que servirá para registro dos relatos.

Assim, considerando que as entrevistas se constituem no nervo da pesquisa e sobre ela os resultados são efetivados, justifica-se uma reflexão acerca dos caminhos e procedimentos metodológicos a serem trilhados na efetivação da coleta de dados orais.

\section{CAMINHOS E PROCEDIMENTOS METODOLÓGICOS DA HISTÓRIA ORAL}

Conforme já mencionado anteriormente e como bem salienta Bom Meihy (1996), a abordagem metodológica da História Oral, em todas as suas tendências, possibilita ao pesquisador documentar o não documentado. Portanto, o uso da documentação oral, via realização de entrevistas acerca de assuntos/temáticas específicas da respectiva pesquisa, utilizando-se da narrativa, equivale às fontes escritas. Logo, a realização da entrevista oral gravada requer alguns cuidados.

Conforme Meihy (1996), toda pesquisa pautada na História Oral depende da realização de entrevistas. No entanto, nem toda entrevista se constitui em História Oral, visto que a entrevista deve ser concebida como uma das etapas da pesquisa e, como tal, se constitui de três degraus a serem considerados: a pré-entrevista, a entrevista e a pós- entrevista.

A pré-entrevista é caracterizada pelo momento de contato com os prováveis colaboradores, expondo o objeto do estudo empreendido, bem como os objetivos a serem alcançados, informando que os mesmos têm total liberdade para contribuírem, ou não, com a sua realização. Esse momento marca o estabelecimento de uma possível relação de parceria e cumplicidade que possibilitará a realização da entrevista propriamente dita nos parâmetros do "dar-se a ver", definidos por Carvalhais (s/d).

Mediante a aquiescência do futuro entrevistado com a participação na pesquisa, nessa etapa da pré-entrevista se prepara o momento do encontro em que ocorrerá a gravação. Nesse sentido, agendam-se datas, locais e horários para a realização e gravação. Importante, nesses contatos prévios, ao solicitar a adesão do sujeito a ser entrevistado, informar e solicitar autorização para gravação em áudio. Informar também que, caso julgue pertinente e necessário, serão garantidos os critérios de anonimato, com adoção de pseudônimos evitando, assim, 
possíveis aborrecimentos. Deve-se cuidar de informar, ainda, que os colaboradores podem desistir da pesquisa a qualquer momento sem sofrerem quaisquer tipos de constrangimentos.

Assim, após vencer os procedimentos da pré-entrevista e obter a aquiescência dos colaboradores contatados, parte-se para o momento que Bom Meihy (1996) denomina de segundo degrau, o da entrevista. Esse momento, vale lembrar, deve ser realizado em datas, horários e locais agendados pelos colaboradores. Há que se ter o cuidado, no entanto, para que sejam locais tranquilos, silenciosos e que garantam certa privacidade tanto para entrevistador quanto para o entrevistado.

Pertinentes às orientações de Portelli (1991), que concebe a entrevista como um momento de troca, como um trabalho conjunto entre entrevistado e entrevistador como "companheiros de diálogo". Para tanto, o pesquisador deve atentar-se para o estabelecimento de um clima propício e favorável, visto que, conforme nos aconselha Gonzáles Rey (2002, p. 8), “[...] a apresentação da pesquisa por meio da criação de um clima de comunicação e de participação facilita o envolvimento por parte das pessoas". Assim, antes de iniciar a gravação das entrevistas, torna-se de mister importância criar um clima de confiabilidade e cumplicidade, entabulando, inicialmente, uma conversa informal com os colaboradores, abordando questões rotineiras do dia a dia da profissão e reforçando, mais uma vez, os objetivos e procedimentos da pesquisa. Após, solicitar ao entrevistado a autorização para iniciar a gravação da entrevista. Esse procedimento atende ao que nos aconselha Bom Meihy (1996):

[...] convém mostrar que, em vez ir direto ao assunto, se o entrevistado for, por estímulo, evidenciando a formação (profissional, por exemplo) e as circunstâncias que o levaram a determinar a participação ficaria mais lógico o contexto e mais clara a objetividade da narrativa (BOM MEIHY, 1996, p. 42).

Essa conversa informal inicial pode propiciar também, conforme nos orienta Delgado (2007, p. 28), criar uma relação de confiança que possa contribuir para o sucesso da entrevista, atentando-se para o fato de que é preciso "[...] saber silenciar, ouvir, estimular lembranças, repetir em voz alta perguntas que não foram entendidas, não falar ao mesmo tempo que o depoente e repetir perguntas delicadas e importantes de diferentes maneiras", haja vista que, conforme salienta a referida autora, “[...] a realização das entrevistas é considerada etapa crucial de qualquer pesquisa que trabalhe com a metodologia da História Oral” (DELGADO, 2007, p. 27). E, reforçando tal afirmativa, referencia-se a Alberti (1990), para quem “[...] é na realização de entrevistas que se situa efetivamente o fazer da História Oral; é para lá que convergem os investimentos iniciais de implantação do projeto de pesquisa, e é de lá que partem os esforços de tratamento do acervo" (p. 45).

Assim, realizadas as entrevistas, entramos no momento que Bom Meihy (1996) denomina de pós-entrevista, quando devemos manter o contato com os colaboradores, inclusive para o encaminhamento da transcrição das entrevistas. Nesse momento da pós-entrevista, o entrevistador deve proceder à transcrição das entrevistas, na íntegra, mantendo os vícios de linguagem. Posteriormente deve remeter a transcrição aos entrevistados para que façam a leitura, conferência, supressão e/ou acréscimos de trechos e falas e, após conceder os direitos de utilização das entrevistas na redação do relatório da pesquisa, em andamento.

Ao encaminhar a transcrição da entrevista para os colaboradores, o pesquisador deve cuidar de informar-lhes que, embora a sua transcrição tenha sido efetivada na íntegra, as falas passariam, após conferência e cessão de direito de uso, por um processo de textualização, quando 
os vícios de linguagem, tais como repetições e interrupções de pensamentos, poderão ser suprimidos.

Importância especial deve ser atribuída ao momento/etapa da transcrição das entrevistas, que preferencialmente deve ser feita pelo próprio pesquisador, atentando para o que nos adverte Meihy (1996), no sentido de que a transcrição se destina à mudança do estágio da gravação oral para o escrito. Portanto, a transcrição das entrevistas constituiu a primeira versão escrita do depoimento. Segundo Meihy (1990), “[...] há três formas de se portar face às transcrições: 1) tradicional, que implica fidelidade absoluta ao que foi dito, 2) conciliatória, que estabelece uma média entre o que foi dito e o que foi convertido em documento, e 3) livre, técnica que se rende às ideias e não às palavras" (p. 28).

A importância de que a transcrição da entrevista seja efetuada pelo próprio pesquisador, encontra respaldo em Fonseca (1996), ao asseverar que se trata de um processo "[...] lento, criativo e carregado de emoções, pois revive-se todo o momento anterior com uma densidade impressionante" (p. 49). Portanto, a autora aconselha que o momento da transcrição seja iniciado imediatamente após a realização das entrevistas para que "[...] os bastidores do encontro possam ser recuperados com maior precisão", haja vista que a transcrição, conforme continua aconselhando a autora:

É o momento de reviver a experiência, de aprofundar-se no conhecimento do outro, de captar e sentir as suas (do narrador) e as minhas (do entrevistador) angústias, certezas, inseguranças nos detalhes de entonação de voz, reticências, silêncios, nas construções e desconstruções de frases, repetições e negações (FONSECA, 1996, p 52).

Assim é relevante que o pesquisador, tão logo realize as entrevistas, proceda à transcrição, na íntegra das mesmas e, posteriormente, encaminhe o texto para os entrevistados, para que procedam à leitura e à conferência, sempre deixando claro que eles têm total liberdade para suprimir e/ou acrescentar frases e trechos que julguem necessários. Nesse momento, é de suma importância que o pesquisador deixe bastante claro para o entrevistado a sua disponibilidade para novos encontros, novos esclarecimentos.

Após a conferência e aprovação dos textos relativos às transcrições das entrevistas por parte dos sujeitos colaboradores, o pesquisador deve providenciar a obtenção da cessão de direito de uso das mesmas, para fins exclusivos na pesquisa. Para tanto, deve-se solicitar a assinatura de um termo de cessão de entrevista, que deve ser mantido em posse do pesquisador.

As narrativas orais, depois de realizada a etapa da transcrição, passam a ter o valor de documento, "[...] semelhante a qualquer outro texto escrito, diante do qual se encontra um estudioso e que, ao ser fabricado, não seguiu forçosamente as injunções do pesquisador" (DUARTE, 2013, p. 36). Assim, vencidas as etapas de produção das fontes orais, de acordo com os procedimentos metodológicos da História Oral (MEIHY, 1996), o pesquisador depara-se com o grande desafio de análise, conforme salienta Delgado:

O maior desafio da análise das entrevistas consiste no fato de, valendo-se de depoimentos individuais e, por decorrência, singulares, construir evidências e estabelecer correlações e análises comparativas que possam contribuir para que os objetivos da pesquisa sejam alcançados da melhor forma possível (DELGADO, 2006, p. 29). 
Diante de tal desafio, encontramos em Santos e Araújo (2007, p. 194), ricas contribuições que sinalizam para a necessidade de um posicionamento quanto à utilização da História Oral como abordagem metodológica de pesquisa que pode ser adotada como técnica ou como método. Conforme salientam os autores,

A História Oral é uma fonte rica e complexa, há, no entanto, uma decisão metodológica a se tomar nesse campo que é a opção de usar essa fonte como uma técnica ou como um método. Utilizada como técnica, a História Oral é subsidiária de outra fonte. Comporta-se, no entanto, como recurso importante para completar falhas ou lacunas constantes de outra documentação. $\mathrm{Na}$ acepção de método, tem o seu lugar como fonte principal da investigação e envolve um conjunto de entrevistas, que funciona como amostragem significativa, expressiva, pela qual, elementos essenciais do universo em análise devem estar presentes. Como método, configura-se, então, como o fundamento da pesquisa com procedimentos claros (SANTOS e ARAÚJO, 2007, p. 194 195).

Salienta-se, portanto, que a História Oral permite ao pesquisador, ao abraçar uma abordagem qualitativa de pesquisa, adotar um híbrido constituído por dois ou mais procedimentos, que podem se relacionar sem causar danos teórico-metodológicos a cada um separadamente.

Em tal hibridismo a História Oral pode, por exemplo, subsidiar a coleta de dados, de saberes e de fazeres acerca da processualidade do ser/se fazer/sendo professores, fornecendo sinais e pistas que possam subsidiar análises e interpretações pautadas em outros procedimentos metodológicos de pesquisa, tais como a Análise de Conteúdo (BARDIN, 1998), Análise documental (VEIGA-NETO, 2002; DONDIS, 2015), como documentos escritos e pictográficos; a Pesquisa-Ação (THIOLLENT, 2011); a Etnografia (ANDRÉ, 1995); a fenomenologia (MERLEAU-PONTY, 1994), entre outras abordagens.

\section{CONSIDERAÇÕES FINAIS}

O diálogo com os autores nos sinalizaram ricas contribuições que a História Oral pode propiciar tanto para a formação quanto para a atuação docente na medida que propicia aos sujeitos de tal processo externalizarem seus saberes e seus fazeres, "[...] documentando o não documentado" (BOM MEIHY, 1996) e contribuindo para a sua socialização de forma a extrapolar seu aprisionamento aos limites impostos pelas paredes da sala de aula. A proposta metodológica dessa abordagem de pesquisa, com sustentação nas entrevistas orais, sua principal matéria prima, pode possibilitar produções materiais que, ao serem socializadas, contribuem, por sua vez, com a produção e mesmo com a ressignificação de outros saberes e de outros fazeres que constituem a dinâmica função docente.

Coadunamos com Carvalhais (s/d) que o momento da entrevista é o estabelecimento de uma possível relação de parceria e cumplicidade, e que esse "dar-se a ver" se caracteriza pela forma(ação) docente. No momento que o entrevistado narra as lembranças de sua formação, de suas concepções teóricas e das diferentes metodologias de ensino, testadas e validadas no cotidiano de suas salas de aulas, abre-se, também, um leque que estimula e possibilita ao entrevistador refletir sobre os seus próprios saberes e fazeres. Uma aprendizagem de mão dupla. 
Embora as entrevistas se constituam como o nervo central da pesquisa apoiada na História Oral, sua abordagem não se restringe a ela, abrindo um profícuo diálogo com outras metodologias, entrelaçando outros saberes e fazeres no ato de pesquisar.

Conclui-se, portanto, que a História Oral contribui para a pesquisas e para a forma(ação) docente ao escrever a história, a partir das vozes dos sujeitos que se encontram no labor do espaço da sala de aula e que muitas vezes foram subjugados em seus saberes e fazeres. A História Oral pode, portanto, contribuir para o não aprisionamento da pluralidade de saberes que são cotidianamente mobilizados, produzidos e reproduzidos no processo de constituição da identidade profissional, trazendo à tona o que os professores sabem e fazem em sua prática docente, e não apenas aquilo que eles deveriam saber e fazer.

\section{REFERÊNCIAS}

ANDRÉ, Marli. Etnografia da prática escolar. Campinas-SP: Papirus, 1995.

BARDIN, Laurence. Análise de Conteúdo. Lisboa: Edições 70, 1988.

BENJAMIN, Walter. O Narrador. In: Magia e técnica, arte e politica. Obras Escolhidas. Trad. Sérgio Paulo Rouanet. São Paulo: Brasiliense, 2012. p. 197-221

BOGDAN, Robert.; BIKLEN, Sari. Investigaşão qualifativa em Educação. 12 ed. Portugal: Porto Editora, 2013.

BOM MEIHY, José Carlos Sebe. Manual de História Oral. São Paulo: Loyola, 1996.

BOM MEIHY, José Carlos Sebe; HOLANDA, Fabiola. História oral: como fazer, como pensar. São Paulo: Contexto, 2010.

BOSI, Ecléa. Memória e Sociedade - lembranças de velhos. São Paulo: Companhia das Letras, 1994.

CAMARGO, Aspásia. História oral e política. In: FERREIRA, Marieta de Moraes (org.). História oral e multidisciplinaridade. Rio de Janeiro: Diadorim, 1993, p. 75-99.

CARVALHAIS, Isabel Estrada. Entrevista... entre vistas... entre olhares. Disponível em https://setemargens.com/entrevista-entre-vistas-entre-olhares/. Acesso em 18 abr. 2020.

DELGADO, Lucilia de Almeida Neves. História Oral - Memória, tempo, identidade. Belo Horizonte-MG: Autêntica, 2006.

DONDIS, Donis. A sintexe da Linguagem visual. São Paulo: Martins Fontes, 2015.

DUARTE, Kleyver Tavares. História da alfabetização: leitura e escrita para surdos (1962-1986). Dissertação (Mestrado em Educação), Programa de Pós-Graduação em Educação, Universidade Federal de Uberlândia, Uberlândia, 2013.

FONSECA, Selva Guimarães. Ser Professor de História: vidas de mestres brasileiros. 1996. Tese (Doutorado em Educação), Universidade de São Paulo, São Paulo, 1996.

GARNICA, Antonio Vicente Marafioti. História Oral e Educação Matemática: de um inventário a uma regulação. Zetetiké, CEMPEM-Unicamp, Campinas, v. 11, n. 19, p. 09-55, 2003.

GONZALES REY, Fernando Luiz. Pesquisa qualitativa em Psicologia - caminhos e desafios. São Paulo: Thomson, 2002.

LOURO, Guacira Lopes. A História (Oral) da Educação: Algumas reflexões. Em Aberto, n. 47, p. 21- 28, jul./set. 1990. 
LUDKE, Menga e ANDRÉ, Marli. Pesquisa em Educação: abordagens qualitativas. 2 ed. São Paulo: EPU, 2013.

MARZOCHI, Andrea Souza. Procedimentos metodológicos de pesquisa com jovens infratores: a importância da história oral. Resgate - Revista Interdisciplinar de Cultura. Vol. XXI, 25/26, jan./dez. 2013, p. 97-102

MERLEAU-PONTY, Maurice. Fenomenologia da percepção. São Paulo: Martins Fontes, 1994.

MOITA, Maria da Conceição. Percursos de formação e de trans-formação. In: NÓVOA, António. (org.). Vidas de Professores. 2 ed. Porto, Portugal: Porto Editora, 2013. p. 111-140.

MOSS, Willian. et al. La Historia Oral. Buenos Aires: Centro Editor de América Latina, 1991.

NÓVOA, António. Vidas de professores. 2 ed. Portugal. Porto: Porto, 2013.

POLLAK, Michel. Memória e Identidade Social. Estudos Históricos. Rio de Janeiro, v. 5, n. 10, 1992, p. 200-215.

PORTELLI, Alessandro. Reserche as na Experiment in Equality. In: The Death of Luigi Trastulli and Others Stoire. Albany: State University of New York press, 1991. p. 29-45.

ROUSSO, Henri. A memória não é mais o que era. In: FERREIRA, Marieta de Moraes \& AMADO, Janaína (coord.). Usos e Abusos da História oral. Rio de Janeiro: Fundação Getúlio Vargas, 2006.

SANTOS, Sonia Maria e ARAÚJO, Osmar Ribeiro de. História Oral: Vozes, narrativas e textos. Cadernos de História da Educação. Uberlândia-MG: EDUFU, n. 6, jan./dez., 2007, p. 191-201.

SANTOS, Sonia Maria. Perspectiva e abordagem da História Oral como método. Uberlândia- MG: Universidade Federal de Uberlândia - NEPHE/NEIAPE/FACED, 2010. (Mimeo).

THIOLLENT, Michel. Metodologia da Pesquisa-Ação. 18 ed. São Paulo: Cortez, 2011

THOMPSON, Paul. A voz do passado. Trad. Lólio Lorenço de Oliveira. São Paulo: Paz e Terra, 1998.

VANSINA, Jan. La tradición oral. 2. ed. Barcelona: Editorial Labor, 1968

VEIGA-NETO, Alfredo. Caminhos investigativos: novos olhares na pesquisa em Educação. Rio de Janeiro: DP\&A, 2002.

\section{Informações dos autores}

Vilmar José Borges

Universidade Federal do Espírito Santo

E-mail:vilmar.geo@gmail.com

ORCID: http://orcid.org/0000-0002-0846-9621

Link Lattes: http://lattes.cnpq.br/2258402424414309

Jullizze Maia Borges

Universidade Federal de Uberlândia

E-mail: jullizze.maia@hotmail.com

ORCID: http://orcid.org/0000-0001-9449-0053

Link Lattes: http://lattes.cnpq.br/5231512587451074 